Adenosine diphosphate $\left(1 \cdot 7-7 \cdot 0 \times 10^{-6} \mathrm{~mol} . / \mathrm{ml} .=\right.$ $0 \cdot 12-0 \cdot 5 \times 10^{-6} \mathrm{~mol} . / \mathrm{gm}$. muscle) likewise initiates tetanic contractions. Adenylic acid (2.6-8.1 $\times 10^{-6}$ $\mathrm{mol} . / \mathrm{ml} .=0.2-0.6 \times 10^{-6} \mathrm{~mol} . / \mathrm{gm}$. muscle) has stimulating effects on the non-curarized preparation, while the curarized muscle only reacts slightly or not at all. Inorganic sodium triphosphate $\left(2-12 \times 10^{-6}\right.$ mol. $/ \mathrm{ml} .=0.15-0.9 \times 10^{-6} \mathrm{~mol} . / \mathrm{gm}$. muscle) and sodium pyrophosphate $\left(2.5-17 \times 10^{-6} \mathrm{~mol} / \mathrm{gm}\right.$. muscle) release tetanic contractions in curarized and non-curarized muscle, while inorganic sodium orthophosphate in amounts of $20 \times 10^{-6} \mathrm{~mol} . / \mathrm{ml}$. $\left(=1.7 \times 10^{-6} \mathrm{~mol} . / \mathrm{gm}\right.$. muscle $)$ is ineffective.

All chemical stimuli were applied iso-osmotically by replacing a corresponding amount of sodium ehloride in the Thyrode solution with the substances in question; $p \mathrm{H}$ of the solution was $7 \cdot 3$.

When applied to smooth muscle (stomach and bladder of the cat by intra-arterial injection, and small intestines of the guinea pig by adding the substance to the surrounding Ringer bath) only adenosine triphosphate initiates strong activity. The threshold dose is approximately $0.3 \times 10^{-6} \mathrm{~mol} . / \mathrm{ml}$. (=0.04 $\times$ $10^{-6} \mathrm{~mol} . \mathrm{gm}$. muscle). The atropinized preparation which is insensitive to strong doses of acetylcholine still reacts to adenosine triphosphate. Adenosine diphosphate $\left(2.5 \times 10^{-6} \mathrm{~mol} . / \mathrm{ml}=0.35 \times 10^{-6}\right.$ mol./gm. muscle), adenosine diphosphate plus orthophosphate $\left(5 \cdot 0+5.0 \times 10^{-6} \mathrm{~mol} . / \mathrm{ml}=\right.$ $0.7+0.7 \times 10^{-6} \mathrm{~mol} / \mathrm{gm}$. muscle), adenylic acid $\left(2 \times 10^{-6} \mathrm{~mol} . / \mathrm{ml} .=0.26 \times 10^{-6} \mathrm{~mol} . / \mathrm{gm}\right.$. muscle $)$, inorganic sodium pyrophosphate $\left(7 \times 10^{-6} \mathrm{~mol} . / \mathrm{ml} .=\right.$ $1.0 \times 10^{-8} \mathrm{~mol}$. $\mathrm{gm}$. muscle) and sodium orthophosphate $\left(14 \times 10^{-6} \mathrm{~mol} . / \mathrm{ml} .=2 \cdot 0 \times 10^{-6} \mathrm{~mol} . / \mathrm{gm}\right.$. muscle) are completely ineffective on the stomach and the bladder of the cat, while pyrophosphate causes contractions in the small intestines of the guinea pig $\left(0.22-0.7 \times 10^{-6} \mathrm{~mol} . / \mathrm{ml}\right.$. $)$. The effect of inorganic triphosphate $\left(6 \times 10^{-6} \mathrm{~mol} . / \mathrm{ml}=0.83 \times\right.$ $10^{-6} \mathrm{~mol} . / \mathrm{gm}$. muscle) is either absent or slight. Thus the action of adenosine triphosphate on smooth musele is highly specific and corresponds to its specific effect on the flow birefringence of purified myosin solutions ${ }^{3}$.

These experiments support the view that adenosine triphosphate is an essential agent in the release of normal muscular contraction.

FrTtz BUChTHat.

Department of Physiology, Grorg Kahlson.

$$
\text { University of Lund. }
$$
June 6 .

Buchthal, F., Deutsch, A., and Knappeis, G. G. [Nature, 153, 774 (1944)?.

${ }^{2}$ Brown, G. L., J. Physiol., 92, 22 P (1938).

${ }^{3}$ Needham, J., Shih-Chang Shen, Needham, D. M., and Lawrence, A. S. C., Niture, 147, 766 (1941). Needham, J., Kleinzeller, A., Miall, M., Dainty, M., Needham, D. M., and Lawrence, A. S. C., Nature, 150, 46 (1942).

\section{Fortification of Pasteurized Cheese with Fish Liver Oils}

A systrmatic search for natural foods that could be fortified with crude fish liver oils in order to supplement the vitamin A content of diets for native troops resulted in peanut-butter containing 5,000 I.U. of vitamin. A per ounce being produced in large quantities. The peanut-butter masks the fishy flavours of the crudest fish liver oil, while the added vitamin has been demonstrated to be stable for six to nine months at high temperatures $\left(85^{\circ}-98^{\circ} \mathrm{F}\right.$.).

Continuing the above systematic search, the possibility of fortifying pasteurized cheese with crude fish liver oils has been investigated during the past year. Stonebasis (Polyprion americanus) liver oil of 610,000 r.v. of vitamin A per gram, diluted with arachis oil to 80,000 I.U. of vitamin A per gram, stockfish (Merlucius capensis) liver oil of 9,370 I.J. of vitamin A per gram and Vaalhaai shark (Galeorhinus canis) liver oil of 26,800 I.U. of vitamin A per gram were added to cheese during the last stages of the pasteurizing process and thoroughly mixed. The degree of fortification aimed at in these experiments was 5,000 r.U. of vitamin A per ounce of cheese. The fortified pasteurized cheese was packed either in $A$ 2 $\frac{1}{2}$ cans and hermetically sealed or in standard ounce packages wrapped in tinfoil. The fortified cheese was stored at room temperatures and at constant temperatures of $85^{\circ}-98^{\circ} \mathrm{F}$.

Vitamin $\mathbf{A}$ in the cheese was determined by the Carr-Price reaction after ether extraction of the unsaponifiable fraction followed by removal of the ether. Losses of vitamin A during saponification, as indicated by Jones and Haines ${ }^{1}$, suggest that the recovery values of 77-80 per cent of the vitamin added to the cheese are lower than the actual values. In no case could more than 90 per cent of the added vitamin $\mathbf{A}$ be recovered with the utmost precautions and refinements in the method of estimation. Some loss of vitamin $\mathbf{A}$ is thus expected in the process of fortification.

Losses of vitamin A during storage for 8-12 months at $85^{\circ} \mathrm{F}$. proved to be less than 10 per cent. Cheese in ounce packages wrapped in tinfoil maintained its vitamin content just as well as cheese packed in hermetically sealed tins.

Only in the case when stockfish liver oil was added (amounting to 2 per cent of the cheese) could any suggestion of fishy flavour be detected, and then only by comparison with control samples.

The feasibility of fortifying pasteurized cheese with crude fish liver oils has thus been demonstrated. Crude liver oils of vitamin A potency ranging from 15,000 to 80,000 I.U. per gram would appear to be most satisfactory. The lower potency oils, such as stockfish liver oils, have to be added in such quantities that the consistency of the cheese is appreciably changed, although at no stage was any sign of fat separation from the emulsion visible.

Rees Davies.

E. BEYERS.

Low Temperature Research Laboratory, Cape Town.

March 27.

1 Jones, J. I. M., and Haines, R. T., The Analyst, 68, 8 (1943).

\section{Role of Protozoa in the Aerobic Purification of Sewage}

DURING recent years, there has been increasing amount of evidence regarding the importance of protozoa in the aerobic purification of sewage ${ }^{1-4}$ and, more recently, some quantitative observations on protozoa in determining the condition of sludge and quality of effluent have been recorded ${ }^{5-10}$. The evidence so far obtained has, however, been only indirect, chiefly owing to the difficulty in separating 